\title{
Morphology and Carbon Isotope Composition of Microdiamonds from Dachine, French Guiana
}

\author{
Letendre, J. ${ }^{1}$, McCandless, T.E. ${ }^{2}$, and Eastoe, C.J. ${ }^{2}$
}

1. Golden Star Resources Ltd., 57 High Street, Kingston, Georgetown, Guyana

2. Center for Mineral Resources, Department of Geosciences, University of Arizona, Tucson, Arizona, USA 85721

The Bureau de Recherches Geologiques et Minieres (BRGM) first recovered diamonds in the Inini basin in 1975 in the course of a regional heavy mineral prospecting campaign. Subsequent follow-up in 1978 confirmed a diamond anomaly in the headwaters of the Grand Inini Creek. Detailed exploration of the IT 33 occurrence by the BRGM from 1979 to 1981 established small alluvial deposits of uncertain economic potential due to the overall small stone size. An ultrabasic rock was identified as a possible source.

A short due diligence campaign on the IT 33 diamond occurrence by Guyanor Ressources (a company held $70 \%$ by Golden Star that operates entirely in French Guiana) in late 1994 confirmed the presence of abundant diamonds in the Dachine project area. A total of 1250 diamonds from 1.6 to $0.25 \mathrm{~mm}$ in size were recovered from seven samples of eluvium and one of alluvium totaling $251 \mathrm{~kg}$. A subset of 464 diamonds from both material types was subjected to a morphological and carbon isotope study to better characterise their source regions in the mantle, and to decipher subsequent processes (e.g., weathering, transport) that the diamonds may have experienced.

Four groups, based mainly on colour, surface featues, and morphology, were defined in an attempt to identify the dominant parageneses present (terminology after McCandless et al., 1994; Robinson, 1979; Robinson et al., 1989). (1) Small to mid-size (200-600 microns diameter) off-white to white, inclusion-bearing octahedra, cubes, and fragments in which xenocrystic surface features dominate; (2) Large (300-1000 microns) brown, heavily included octahedra and tetrahexahedroida, and derivative fragments, with macrodiamond surface features dominating; (3) Small (200-600 microns) white to off-white, slightly included single octahedra, cubes, tetrahexahedroida, and derivative fragments mainly with macrodiamond surface features dominating; (4) Small to mid-size (200-600 microns), apparently body-coloured stones, including pale pink, green, yellow, and gray octahedra, cubes, and tetrahexahedroida. The brown colour of diamonds in group 2 may be due in part to the abundance of black-brown inclusions. Group 1 is expected to represent diamonds derived mainly from xenolithic material, whereas group 2 and 3 may represent macrodiamonds. Group 2 diamonds have about twice the percentage of diamonds greater than 400 microns compared to groups 1,3 , and 4 . Group 2 diamonds also include more fragments than group 1 diamonds, which would be anticipated if group 2 diamonds are the fragments of larger, inclusion-bearing diamonds, making them more susceptible to breakdown due to internal stresses. The difference in inclusion abundance, size and morphology for the diamonds comprising group 1 and 2 suggests that at least 2 diamond parageneses may be present in the igneous host. One paragenesis consists of larger, heavily included diamonds and the other consists of smaller, less included diamonds. The many body colours that comprise group 4 diamonds probably represent a number of other minor parageneses.

The most common resorption surface on the diamonds is the low-relief surface. Low-relief surfaces are the most dominant resorption surface of diamonds from lamproites such as at Prairie Creek, where it is present on $94 \%$ of the macrodiamonds (McCandless et al., 1994). The similarities suggest that the French Guyana diamonds may have been derived from a lamproitic igneous host, or at the least, an igneous host with volatile compositions (i.e. $\mathrm{H}_{2} \mathrm{O} / \mathrm{CO}_{2}$ ratios) similar to lamproites.

During resorption, larger diamonds are exposed early on and experience the greatest amount of resorption, which is supported by the positive correlation between the percentage of stones $>400$ microns in size, and the percentage of macrocrystic surface features present, particularly for groups 2 
and 3. Diamonds break during resorption and it appears that most breakage surfaces have some evidence of resorption. Smaller diamonds exhibit xenocrystic surface features and some have uneven resorption. Some of the largest diamonds exhibit xenocrystic surface features, some being relatively inclusion-free group 1 diamonds. These are the most attractive with respect to colour and the lack of inclusions.

Diamonds at surface conditions are under high internal stress due to expansion of included minerals. This leads to fracture and disaggregation, which is the most dominant weathering process for the French Guiana diamonds. This process is independent of whether the diamonds are transported, and can occur in situ while the diamonds are in the igneous host. Once exposed to meteoric water, black opaque inclusions in the diamonds are altered to secondary material comprised of Feoxide/hydroxides and clays. Indentations in irregularly-shaped diamonds, occupied by other primary minerals, protected these areas of the diamond until resorption had largely ended. Weathering removes these adjoining minerals, leaving unresorbed low areas of diamond surrounded by high points with low-relief surfaces. Primary inclusions or intergrowths of other minerals with the diamonds are very rare. In one diamond, an intergrowth/inclusion exhibits a corrosion texture that is typical of silicates exposed to lateritization or calcretization, indicating that the diamonds have been in a weathering environment dominated by chemical weathering. Although the green and yellow colours of some diamonds appear to be body colours, it is possible that the colouration is due to staining by $\mathrm{Fe}$-oxide/hydroxide minerals during weathering or to radiation damage by uranium or thorium in groundwater.

None of the diamonds bear resemblance to diamonds derived from alluvial sources. There are a number of fragile fragments that would not survive transport under typical fluvial bedload conditions (McCandless, 1990). Some of the largest diamonds are also cracked octahedra that would not travel far in a bedload environment before breaking down. Thus it was determined thatt they are not far removed from their igneous host.

There are also a large number of cubes and cube-octahedra in the Dachine microdiamonds. Given that lamproites attack diamonds vigorously, and peridotite xenoliths are more easily disaggregated than eclogite, it was considered that the cube diamonds have survived because they are derived from eclogite. Two octahedra, one cube and one cube-octahedra were analysed from group 1 . Three of the diamonds are ${ }^{13} \mathrm{C}$-depleted, with $\delta^{13} \mathrm{C}$ ratios centred at $-27 \%$, and one octahedron is heavier at $-12.6 \%$ (Figure 2a). Group 1 diamonds are dominated by xenolithic surface features and it was anticipated that these diamonds are eclogitic. The heaviest diamonds analysed are found in group 3 , with an octahedron and octahedral fragment at -8.1 and $-10.5 \%$, respectively. The next heaviest diamond is also in group 3 , a cube with $\delta^{13} \mathrm{C}=-13.7 \%$. The remaining diamonds in group 3 are an irregular, a fragment, and a cube-octahedron with $\delta^{13} \mathrm{C}$ ratios centred around $-25 \%$. Five group 4 diamonds were analysed; a cube, octahedral fragment, and tetrahexahedroidal fragment centre around $-26 \%$, a fragment and an irregular have heavier values of -19.4 and $-17.0 \%$, respectively.

The results suggest a dominant eclogitic paragenesis with $\delta^{13} \mathrm{C}$ ratios from -23 to $-27 \%$. Three of the nine diamonds within this range are also the xenocrystic diamonds of group 1 . Of the three group 3 diamonds that fall within this range, one is distorted and exhibits ribbing, which also supports a xenocrystic origin. One group 4 diamond within this range exhibits lamination lines, also supporting a xenolith origin. Though not conclusive, the features suggest that many of the diamonds that exhibit macrocrystic surfaces in group 3 and 4 are probably derived from the same source as the xenocrystic diamonds of group 1 . The three group 4 diamonds that fall in this range include a yellow cube, a pink octahedral fragment, and a green tetrahexahedroidal fragment. Assuming these diamonds are all from the same source, this suggests that a variety of coloured diamonds occur in the same paragenesis. 
Four diamonds cluster at isotopically heavier values from -8.1 to $-13.7 \%$. These diamonds may represent a different paragenesis, as three of the four are whole crystals that are $\geq 400$ microns in size and exhibit macrocrystic surface features (Table 1). Uneven resorption on the isotopically heaviest diamond, however, also supports a xenocryst origin for these diamonds.

The primary morphology, surface features, and carbon isotopes for the Dachine microdiamonds suggest that they are derived from mantle sources, particularly eclogite. Secondary surface features on the microdiamonds indicate that they were transported in a strongly resorbing host magma, such as a lamproite or other igneous host with a high $\mathrm{H}_{2} \mathrm{O} / \mathrm{CO}_{2}$ ratio. Subsequently, the microdiamonds were exposed to chemical weathering, and transported a very short distance from their igneous host..

\section{References:}

McCandless, T.E., 1989, Microdiamonds from the Sloan 1 and 2 kimberlites, Colorado, USA: Extended Abstracts, Workshop on Diamonds, 28th International Geological Congress, Washington, D.C., pp.44-46.

McCandless, T.E., 1990, Kimberlite xenocryst wear in high energy fluvial systems: experimental studies. J. Geoch. Expl., 37, p.323-331.

McCandless, T.E., Waldman, M.A. and Gurney, J.J., 1994, Macro- and microdiamonds from Arkansas lamproites: morphology, inclusions, and isotope geochemistry: In: H.O.A.Meyer and O.H. Leonardos, (Eds.), 5th International Kimberlite Conference, Volume 2, Diamonds: Characterization, Genesis and Exploration, pp.78-97. CPRM Special Publication 1/B Jan/94, Companha de Pesquisa de Recursos Minerais, Brasilia, Brazil.

McCandless, T.E. and Gurney, J.J., 1995, Microdiamonds from kimberlites and lamproites: observations and ideas concerning their origin: Extended Abstracts, 6th International Kimberlite Conference, Siberian Branch, Russian Academy of Sciences, Novosibirsk, Siberia, 368-370.

Robinson, D.N., 1979, Surface textures and other features of diamonds. Ph.D. thesis, University of Cape Town, South Africa.

Robinson, D.N., Scott, J.N., van Niekerk, A., and Anderson, V.G., 1989, The sequence of events reflected in the diamonds of some southern African kimberlites. Geol. Soc. Australia Sp. Pub. 14, p.990-999. 